\title{
Low-Viscosity Ether-Functionalized Ionic Liquids as Solvents for the Enhancement of Lignocellulosic Biomass Dissolution
}

\author{
Asyraf Hanim Ab Rahim ${ }^{1}$, Normawati M. Yunus ${ }^{1, *(D)}$, Wan Suzaini Wan Hamzah ${ }^{1}$, Ariyanti Sarwono ${ }^{2}$ and \\ Nawshad Muhammad ${ }^{3}$ \\ 1 Centre of Research in Ionic Liquids (CORIL), Department of Fundamental and Applied Sciences, \\ Universiti Teknologi PETRONAS, Seri Iskandar 32610, Perak, Malaysia; \\ asyrafhanim92@gmail.com (A.H.A.R.); wansuzaini@gmail.com (W.S.W.H.) \\ 2 Department of Environmental Engineering, Pertamina University, Jalan Teuku Nyak Arief, Simprug, \\ Kebayoran Lama, Jakarta 12220, Indonesia; arisarwono3@gmail.com \\ 3 Institute of Basic Medical Sciences, Khyber Medical University, Peshawar, Khyber Pakhtunkhwa 25100, Pakistan; \\ nawshadchemist@yahoo.com \\ * Correspondence: normaw@utp.edu.my
}

Citation: Rahim, A.H.A.; Yunus, N.M.; Hamzah, W.S.W.; Sarwono, A.; Muhammad, N. Low-Viscosity Ether-Functionalized Ionic Liquids as Solvents for the Enhancement of Lignocellulosic Biomass Dissolution. Processes 2021, 9, 261. https://doi.org/ $10.3390 /$ pr9020261

Received: 31 December 2020

Accepted: 27 January 2021

Published: 29 January 202

Publisher's Note: MDPI stays neutral with regard to jurisdictional claims in published maps and institutional affiliations.

Copyright: (c) 2021 by the authors. Licensee MDPI, Basel, Switzerland. This article is an open access article distributed under the terms and conditions of the Creative Commons Attribution (CC BY) license (https:/ / creativecommons.org/licenses/by/ $4.0 /)$.

\begin{abstract}
Due to the substantial usage of fossil fuels, the utilization of lignocellulosic biomass as renewable sources for fuels and chemical production has been widely explored. The dissolution of lignocellulosic biomass in proper solvents is vital prior to the extraction of its important constituents, and ionic liquids (ILs) have been found to be efficient solvents for biomass dissolution. However, the high viscosity of ILs limits the dissolution process. Therefore, with the aim to enhance the dissolution of lignocellulosic biomass, a series of new ether-functionalized ILs with low viscosity values were synthesized and characterized. Their properties, such as density, viscosity and thermal stability, were analyzed and discussed in comparison with a common commercial IL, namely 1-butyl3-methylimidazolium chloride (BMIMCl). The presence of the ether group in the new ILs reduces the viscosity of the ILs to some appreciable extent in comparison to BMIMCl. 1-2(methoxyethyl)-3methylimidazolium chloride (MOE-MImCl), which possesses the lowest viscosity value among the other ether-functionalized ILs, demonstrates an ability to be a powerful solvent in the application of biomass dissolution via the sonication method. In addition, an optimization study employing response surface methodology (RSM) was carried out in order to obtain the optimum conditions for maximum dissolution of biomass in the solvents. Results suggested that the maximum biomass dissolution can be achieved by using 3 weight $\%$ of initial biomass loading with $40 \%$ amplitude of sonication at $32.23 \mathrm{~min}$ of sonication period.
\end{abstract}

Keywords: biomass; dissolution; ionic liquids; ultrasonic; optimization; RSM

\section{Introduction}

A rapid growth in world population has led to high demand in fuel and chemicals supply [1]. The annual consumption of petroleum in 2007 was at $4.4 \times 10^{6}$ tons per year with $10 \%$ utilization for petrochemical feedstocks [2,3]. High demand for raw materials supplies in the chemical production industry has led to elevated prices of petroleum due to its limited source. A statement provided by BP on World Energy Day in 2014 suggested that the raw crude oil supply will only be able to last for 53.3 years [4]. Therefore, due to this alarming situation, the search for new renewable feedstock has become the main target for researchers.

Lignocellulosic biomass, an inedible portion of dry plant materials, contains cellulose, hemicellulose and lignin, and this biomass is typically disposed of by combustion [5]. Since decades ago, lignocellulosic biomass has gain researcher interest as a new alternative chemical feedstock as it is abundantly available and easily obtained through agriculture activities [6,7]. This signifies a large supply with affordable cost for biofuel and chemical 
production [6,8]. Numerous studies have shown that all biomass constituents have the potential to be converted into various simple chemicals such as fuel ethanol, furfural, lactic acid, phenolic aldehydes and cyclohexane $[9,10]$. However, due to the high recalcitrance of lignocellulosic biomass, mainly towards organic solvents, which is due to amphiphilic properties of cellulose, the search for the suitable solvents for dissolution is a crucial step prior to any conversion processes in order to extract all constituents and reduce the biomass crystallinity thus, in turn, helps to improve cellulose accessibility $[7,11]$. Several pretreatment methods have been developed, such as ammonia explosion, acid and alkali pretreatment [12]. However, these processes suffer several drawbacks, such as the generation of a huge amount of wastes into the environment, the requirement of expensive catalysts and the formation of undesirable compounds [13,14].

Ionic liquids (ILs) have been recognized as potential solvents for dissolving biomass and extracting cellulose, hemicellulose and lignin. Generally, an IL is defined as a molten salt, composed entirely of ions and has a melting point lower than $100{ }^{\circ} \mathrm{C}$ [15]. The availability of numerous anions and cations combinations allows ILs to be synthesized based on applications of interest with tunable properties. In addition, ILs possess exceptional physical properties such as broad liquidus range, negligible vapor pressure and high thermal stability $[16,17]$. As a large portion of lignocellulosic biomass consists of cellulose with the amphiphilic property [18], ILs have been recognized as a potential pretreatment solvent to dissolve lignocellulosic biomass. Nevertheless, ILs normally possess high viscosity values, and this provides the main challenge in the application of ILs as solvents for lignocellulosic biomass dissolution. Highly viscous ILs such as 1-butyl-3-methylimidazolium chloride (BMIMCl) and 1-ethyl-3-methylimidazolium chloride (EMIMCl) cause a reduction in the mass transfer of solute during dissolution, and this eventually leads to the decline of the percentage of biomass dissolved in the ILs. The studies conducted by Fukaya et al. and Zhang et al. have shown that ally-based ILs with lower viscosity values as compared to alkyl-based ILs demonstrated better dissolution ability [19,20].

Therefore, the introduction of various functionalized groups has been explored to alter the viscosity of ILs. In order to reduce the viscosity of ILs, an ether functional group has been proposed to replace one of the methylene groups, $\mathrm{CH}_{2}$, in the alkyl chain structure of the ILs. Unlike the carbon atom, which forms bonds with four atoms in the alkyl chain, the oxygen atom in the ether functional group may only bond to another two atoms, and this provides rotational flexibility to the structure of the ILs and consequently reduces the viscosity of the ILs. However, this theory is vaguely discussed. The molecular dynamic study done by Siqueira and Ribeiro has shown that flexible alkyl chain has resulted in less effective structure assembly, which then caused a reduction in ILs viscosity [21]. Although the work related to low viscosity ILs as solvents for biomass dissolution has extensively been done, the combination of ether-functionalized ILs with the implementation of sonication has not yet been reported in detail. Previously, our group has reported a comparison study between ether-functionalized and non-functionalized ILs for bamboo biomass dissolution [22]. Therefore, to further explore the effect of ether-functionalized ILs towards biomass dissolution, another three ether-functionalized, which include alkoxyethyl and alkoxymethyl groups, ILs were synthesized. Additionally, the effect of two different ether groups, which are methoxyethyl and methoxymethyl, towards melting point and thermal stability, was also discussed.

In addition, the present work was carried out to determine the optimization condition for biomass dissolution in newly synthesized ether-functionalized ILs assisted by sonication using response surface methodology (RSM). RSM is an empirical model involving mathematical and statistical methods to analyze the proposed experimental condition with an objective to obtain an alternative strategy for various processes and optimize selected variables to find the best performance for the selected response [23]. The RSM study normally involves multiple steps, which are (1) preliminary study for identifying independent variables that affect the response, (2) the selection of suitable experimental design and experimental works, (3) statistical analyses, (4) the evaluation of model fitness, 
(5) model verification, and (6) getting an optimum value for each variable [24]. In this work, the preliminary study was performed at conditions that were predetermined during the screening process of selecting the best IL for the optimization study. Further work focusing on the optimization process using selected ether-functionalized IL and model validation was carried out by using RSM.

\section{Materials and Methods}

\subsection{Materials}

Chemicals of analytical grade were used without further purification process for the synthesis of ether-functionalized ILs and biomass dissolution. The CAS number, source and grades of the chemicals used are as follows: 1-methylimidazole (616-47-7, Merck, 98\%), 1-butylimidazole (4316-42-1, Merck, 98\%), 2-chloroethyl methyl ether (627-42-9, Merck, 98\%), chloromethyl ethyl ether (3188-13-44, Sigma-Aldrich, 95\%), 2-chloroethyl ethyl ether (628-34-2, Sigma-Aldrich, 99\%), dimethyl sulfoxide (67-68-5, Merck, 99.9\%), dichloromethane (75-09-2, Merck, 99.9\%), diethyl ether (60-29-7, Merck, 99.9\%), ethyl acetate (141-78-6, Merck, 99.9\%), 1-butyl-3-methylimidazolium chloride (79917-90-1, Merck, 99\%).

The bamboo biomass from species of Gigantochloa scortcheninii, a native plant of Malaysia commonly known as "buluh semantan", was obtained from the bamboo processing industry in Seri Iskandar, Malaysia. The bamboo was ground into a powder and sieved into particle sizes of $<500 \mu \mathrm{m}$ by Retsch Test Sieve, AS 200.

\subsection{Synthesis of Ether-Functionalized ILs}

The synthesis procedure for each ether-functionalized ILs is described in this section. The structural confirmation of the synthesized ether-functionalized ILs was done by ${ }^{1} \mathrm{H}$ and ${ }^{13} \mathrm{C}$ NMR (Bruker Advance III, $500 \mathrm{MHz}$ ) and DMSO-d 6 was used as a solvent. The ${ }^{1} \mathrm{H}$ and ${ }^{13} \mathrm{C}$ chemical shifts are reported in part per million (ppm). The multiplicities are abbreviated as singlet (s), duplet (d), triplet (t) and multiplet (m). The structures of the ILs are shown in Figure 1, and the NMR results are also given in this section.

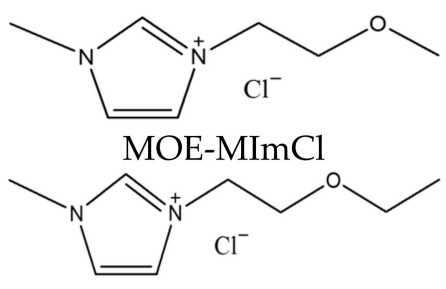

EOE-MImCl

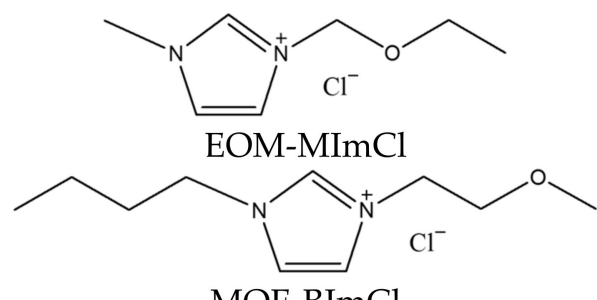

MOE-BImCl

Figure 1. Structures of ether-functionalized ionic liquids (ILs).

\subsubsection{1-(2-Methoxyethyl)-3-Methylimidazolium Chloride (MOE-MImCl)}

An equal molar of 2-chloroethyl methyl ether was added into a $50 \mathrm{~mL}$ round-bottomed flask containing $0.05 \mathrm{~mol}$ of 1-methylimidazole. The mixture was refluxed at a temperature of $80{ }^{\circ} \mathrm{C}$ for $48 \mathrm{~h}$ with continuous stirring resulted in an amber color liquid. Then, $15 \mathrm{~mL}$ of ethyl acetate was added into the IL, and the mixture was shaken several times to remove excess reactants. Ethyl acetate was then removed under reduced pressure using a rotary evaporator. This step was repeated five times to ensure complete removal of excess reactant.

${ }^{1} \mathrm{H}$ NMR (500 MHz, DMSO-d 6 ): $\delta 9.536$ (s, 1H, (imi)), 7.887 (d, 1H, (imi)), 7.833 (d, 1H, (imi)), 4.402-4.422 (t, 2H, CH$), 3.3661-3.681,\left(\mathrm{t}, 2 \mathrm{H}, \mathrm{CH}_{2}\right), 3.902\left(\mathrm{~s}, 3 \mathrm{H}, \mathrm{CH}_{3}\right), 3.240(\mathrm{~s} .3 \mathrm{H}$, $\left.\mathrm{CH}_{3}\right),{ }^{13} \mathrm{C}$ NMR $\left(500 \mathrm{MHz}, \mathrm{DMSO}-\mathrm{d}_{6}\right): \delta 137.43123 .87,123.05,70.05,58.48,48.92,36.16$.

\subsubsection{1-Ethyoxymethyl-3-Methylimidazolium Chloride (EOM-MImCl)}

$0.05 \mathrm{~mol}$ of 1 -methylimidazole was dissolved in $30 \mathrm{~mL}$ dichloromethane (DCM). The reaction was stirred continuously at room temperature for a few hours. Then, the flask was immersed in an ice bath. As the temperature reached $0{ }^{\circ} \mathrm{C}, 0.05 \mathrm{~mol}$ of chloromethyl ethyl ether was added dropwise. The mixture was continuously stirred at room temperature 
for $6 \mathrm{~h}$. DCM was then removed using a rotary evaporator. The resulting white solid was washed with $20 \mathrm{~mL}$ diethyl ether three times to remove the unreacted reactant. Diethyl ether was removed under vacuum.

${ }^{1} \mathrm{H}$ NMR (500 MHz, DMSO-d $)$ ): $\delta 9.660$ (s, 1H, (imi)), 7.943 (d, 1H, (imi)), 7.862 (d, 1H, (imi)), $5.624\left(\mathrm{~s}, 2 \mathrm{H}, \mathrm{CH}_{2}\right) 3.919\left(\mathrm{~s}, 3 \mathrm{H}, \mathrm{CH}_{3}\right) 3.540-3.554\left(\mathrm{~m}, 2 \mathrm{H}, \mathrm{CH}_{2}\right), 1.091-1.119(\mathrm{t}, 3 \mathrm{H}$, $\left.\mathrm{CH}_{3}\right),{ }^{13} \mathrm{C}$ NMR $\left(500 \mathrm{MHz}, \mathrm{DMSO}-\mathrm{d}_{6}\right): \delta 137.84,124.41,122.36,78.14,65.00,36.37,15.06$.

\subsubsection{1-(2-Ethoxyethyl)-3-Methylimidazolium Chloride (EOE-MImCl)}

$0.05 \mathrm{~mol}$ of 2-chloroethyl ethyl ether was added into a $50 \mathrm{~mL}$ round-bottomed flask containing $0.05 \mathrm{~mol} 1$-methylimidazole. The reaction was stirred continuously for $96 \mathrm{~h}$ at $80{ }^{\circ} \mathrm{C}$ resulting in a yellowish color liquid. The IL was washed with $15 \mathrm{~mL}$ of ethyl acetate five times to remove excess reactants. Ethyl acetate was then dried under vacuum pressure.

${ }^{1} \mathrm{H}$ NMR (500 MHz, DMSO-d 6 ): $\delta 9.530$ (s, 1H, (imi)), 7.887 (d, 1H, (imi)), 7.833 (d, 1H, (imi)), 4.402-4.422 (t, 2H, CH $), 3.3661-3.681$, (t, 2H, $\left.\mathrm{CH}_{2}\right), 3.902$ (s, 3H, $\left.\mathrm{CH}_{3}\right), 3.240$ (s. 3H, $\left.\mathrm{CH}_{3}\right),{ }^{13} \mathrm{C}$ NMR $\left(500 \mathrm{MHz}, \mathrm{DMSO}-\mathrm{d}_{6}\right): \delta 137.40,123.86,123.08,68.01,65.92,49.18,36.18,15.33$.

\subsubsection{1-(2-Methoxyethyl)-3-Butylimidazolium Chloride (MOE-BImCl)}

An equal molar of 2-chloroethyl methyl ether was added into a $50 \mathrm{~mL}$ round-bottomed flask containing 0.05 mol of 1-butylimidazole. The mixture was refluxed with continuous stirring at temperature $80{ }^{\circ} \mathrm{C}$ for a week resulting in a viscous, yellowish liquid. Ethyl acetate was added, and the mixture was shaken several times to remove an unreacted reactant. Ethyl acetate was then discarded while the excess solvent was removed using a rotary evaporator.

${ }^{1} \mathrm{H}$ NMR (500 MHz, DMSO-d $\left.)_{6}\right): \delta 9.362$ (s, 1H, (imi)), 7.843 (d, 1H, (imi)), $7.812(\mathrm{~d}, 1 \mathrm{H}$, (imi)), 4.367-4.385 (t, 2H, CH 2$), 4.192-4.221\left(\mathrm{t}, 2 \mathrm{H}, \mathrm{CH}_{2}\right), 3.682-3.702\left(\mathrm{~m}, 2 \mathrm{H}, \mathrm{CH}_{2}\right), 3.261$ $\left(\mathrm{s}, 3 \mathrm{H}, \mathrm{CH}_{3}\right), 1.1742-1.801\left(\mathrm{~m}, 2 \mathrm{H}, \mathrm{CH}_{2}\right), 1.223-1.268\left(\mathrm{~m}, 2 \mathrm{H}, \mathrm{CH}_{2}\right), 0.895-0.912\left(\mathrm{~m} .3 \mathrm{H}, \mathrm{CH}_{3}\right)$, ${ }^{13} \mathrm{C}$ NMR (500 MHz, DMSO-d 6 ): $\delta$ 137.02, 123.20, 122.74, 70.03, 58.43, 49.00, 48.90, 31.84, $19.21,13.00$.

\subsection{Characterization of Ether-Functionalized ILs}

The structural confirmation of the synthesized ether-functionalized ILs was done by ${ }^{1} \mathrm{H}$ and ${ }^{13} \mathrm{C}$ NMR (Bruker Advance III, $500 \mathrm{MHz}$ ) and DMSO- $\mathrm{d}_{6}$ was used as a solvent. The ${ }^{1} \mathrm{H}$ and ${ }^{13} \mathrm{C}$ chemical shifts are reported in part per million (ppm). The multiplicities are abbreviated as singlet (s), duplet (d), triplet (t) and multiplet (m).

The thermal stability measurement of ether-functionalized ILs was done by using TGA (PerkinElmer, STA 6000). An approximate $5.00 \mathrm{mg}$ sample was loaded in a crucible pan, and the measurement was carried out with a heating rate at $10^{\circ} \mathrm{C} / \mathrm{min}$ in the temperature range at $50-650{ }^{\circ} \mathrm{C}$ under $20 \mathrm{~mL} / \mathrm{min}$ nitrogen flow.

The calorimetric measurements were done by employing DSC (Mettler Toledo, DSC-1) in the temperature range of -150 to $150{ }^{\circ} \mathrm{C}$ at a heating rate of $10^{\circ} \mathrm{C} / \mathrm{min}$. Each sample was weighed to approximately $10.00 \mathrm{mg}$ and sealed in aluminum pans. The samples were cooled to the temperature of $-150{ }^{\circ} \mathrm{C}$ at the rate of $10^{\circ} \mathrm{C} / \mathrm{min}$ before heating to $150{ }^{\circ} \mathrm{C}$ at the same rate. The data were collected at the second cooling heating scan.

The measurements of viscosity and density of ether-functionalized ILs were done simultaneously by using SVM 3000 from Anton Parr. Then, 4-5 mL of samples were injected by using a $5 \mathrm{~mL}$ syringe into the instruments, and the measurement was carried out at atmospheric pressure in the temperature range of 293.15-363.15 K.

\subsection{Dissolution of Bamboo in Ether-Functionalized ILs}

Bamboo biomass ( $5 \mathrm{wt} \%$ ) was added into a $16 \mathrm{~mL}$ vial containing $2.0 \mathrm{~g}$ of IL. The dissolution of biomass was done using a direct $6 \mathrm{~mm}$ sonication probe couples with Sonic Vibra Cell processor with power and frequency of $500 \mathrm{~W}$ and $20 \mathrm{kHz}$, respectively. The probe sonicator was inserted into the mixture IL/biomass to a point about $1 / 3$ of the total height from the surface to ensure optimum acoustic power supply [25]. The performance 
of biomass dissolution was quantitatively measured based on the method suggested by Sun et al. [26]. The mixture was added into a beaker containing DMSO and stirred for 30 min. The precipitate was separated under centrifugation $(4000 \mathrm{rpm}, 15 \mathrm{~min})$ and washed with distilled water a few times to remove excess ILs. The precipitate was dried in an oven at $80{ }^{\circ} \mathrm{C}$ for $6 \mathrm{~h}$. The calculation for the percentage of biomass dissolution in ILs is shown in Equation (1):

$$
\text { Dissolution percentage }=[(\mathrm{Wi}-\mathrm{Wp}) / \mathrm{Wi}] \times 100
$$

$\mathrm{Wi}$ is the initial mass of sample loading, and $\mathrm{Wp}$ is the undissolved residue left after the addition of DMSO. It must be noted that the addition of DMSO did not cause the dissolution of biomass as biomass has a more complicated structure, which prevents it from dissolving in DMSO. This was proven by functional group analysis done by Sun and coworkers in which the collected undissolved residue spectra were in line with spectra of biomass before undergoing dissolution [26].

\section{Optimization of Bamboo Dissolution in Ether-Functionalized ILs}

This part of the study investigates the effect of three independent variables towards bamboo biomass dissolution in the selected ether-functionalized IL by employing BoxBehnken (BB) design using Design Expert. The objective of the experimental design is to optimize the response variables, which is the percentage of biomass dissolved. The IL chosen is $\mathrm{MOE}-\mathrm{MImCl}$ because it exhibits the best biomass dissolution performance during the initial stage of the study. Three independent variables, which are ultrasonic amplitude (A, 20 to 40\%), the period of sonication (B, 10 to $60 \mathrm{~min}$ ) and initial biomass loading (C, 2.0 to $8.0 \mathrm{wt} \%$ ), were studied at three levels for a total of 17 runs with five repetitions at the central point as shown in Table 1, and the percentage of bamboo dissolved in ILs reported as the response.

Table 1. Experimental design for response surface methodology (RSM).

\begin{tabular}{cccccc}
\hline \multirow{2}{*}{ Variables } & \multirow{2}{*}{ Coding } & \multirow{2}{*}{ Unit } & \multicolumn{3}{c}{ Coded Level Experiments Factor } \\
\cline { 4 - 6 } & & & $-\mathbf{1}$ & $\mathbf{0}$ & $\mathbf{1}$ \\
\hline Ultrasonic amplitude & $\mathrm{A}$ & $\%$ & 20 & 30 & 40 \\
Period of sonication & $\mathrm{B}$ & minutes & 10 & 35 & 60 \\
Initial biomass loading & $\mathrm{C}$ & $\mathrm{wt} \%$ & 2 & 5 & 8 \\
\hline
\end{tabular}

The lowest and highest points for each variable were selected based on the literature review and preliminary studies. The experimental data obtained were analyzed for the determination of significance level using one-way analysis of variance (ANOVA) [27]. Meanwhile, the model equation proposed by design was validated by carrying out experiments based on the suggested solution for optimum conditions.

\section{Results}

\subsection{Thermal Properties of Ether-Functionalized ILs}

\subsubsection{Thermal Stability}

Various studies that have been carried out suggested that the introduction of ether will alter the thermal properties of ILs by reducing their thermal stability and melting point in comparison to imidazolium ILs without ether group [28-30]. Table 2 lists the onset temperature $\left(\mathrm{T}_{\mathrm{o}}\right)$ for synthesized ether-functionalized ILs, and the result was compared with $\mathrm{BMIMCl}$ from a previous publication [31]. The incorporating of ether should have reduced the $T_{0}$ of ether-functionalized ILs as compared to BMIMCl due to the weak electrostatic interactions between cation and anion caused by the electron-donating effect, as can be seen in EOM-MImCl [32,33]. However, the opposite result was observed for $\mathrm{MOE}-\mathrm{MImCl}$, EOE-MImCl and $\mathrm{MOE}-\mathrm{BImCl}$ in which their $\mathrm{T}_{\mathrm{O}}$ do not significantly differ from $\mathrm{BMIMCl}$ at the same reaction rate. Besides this, $\mathrm{EOM}-\mathrm{MImCl}$ with the substituent group of alkoxymethyl showed a noticeable reduction in $\mathrm{T}_{\mathrm{o}}$. This may be due to the short 
space that exists between the alkoxy oxygen atom and quaternary nitrogen atom as it is only separated by one methylene group in the cation's structure as compared to ILs with alkoxyethyl group [34].

Table 2. Onset, glass transition and melting temperature for ILs.

\begin{tabular}{cccc}
\hline Ionic Liquids & $\mathbf{T}_{\mathbf{o}}\left({ }^{\circ} \mathbf{C}\right)$ & $\mathbf{T}_{\mathbf{g}}\left({ }^{\circ} \mathbf{C}\right)$ & $\mathbf{T}_{\mathbf{m}}\left({ }^{\circ} \mathbf{C}\right)$ \\
\hline MOE-MImCl & 273.13 & -86.45 & - \\
EOM-MImCl & 178.00 & -83.84 & - \\
EOE-MImCl & 267.88 & -91.43 & - \\
MOE-BImCl & 264.76 & -69.09 & - \\
BMIMCl & 268.89 & - & 74.1 \\
\hline
\end{tabular}

\subsubsection{Phase Transition}

The study on ILs phase transition behavior was done by DSC in the temperature range of -150 to $150^{\circ} \mathrm{C}$. Table 2 shows the glass transition $\left(T_{g}\right)$ and melting temperature $\left(\mathrm{T}_{\mathrm{m}}\right)$ of all synthesized ether-functionalized ILs. Based on the DSC measurement, all ether-functionalized ILs displayed glass transition behavior instead of melting. These phase transition behavior of ether-functionalized ILs were different as being compared with IL without the presence of ether group, and this is supported by the presence of $\mathrm{T}_{\mathrm{m}}$ in the phase transition of BMIMCl as shown in Table 2 [31]. In general, this type of behavior observed in ether-functionalized ILs indicates the formation of amorphous glass compounds during the cooling process, and reformation of the liquid phase on the heating stage without the crystallization process occurred [35]. The structural flexibility of ether in the alkyl side chain of ether-functionalized ILs had increased the rotational freedom, thus suppressing the ILs crystallization ability.

\subsubsection{Density}

The density and viscosity measurements were carried out for all ether-functionalized ILs except for EOM-MImCl due to its solid appearance, which is not suitable for viscosity measurement. The experimental density values for ether-functionalized ILs and BMIMCl are given in Figure 2. In the ether-functionalized ILs family, the density of ILs reduced as the alky chain increased from methyl to butyl group. Similar cases were observed in tetraalkylammonium, trialkyl sulfonium and 1,2,3-dialkyimidazolium-based ILs [36,37]. The cation size becomes larger as the alkyl chain gets longer, thus leads to unfavorable packing in IL structure, which in turn contributes to the high-density of ether ILs [37]. To highlight the effect of ether in ILs density, a similar measurement was done for BMIMCl. According to Zhang and coworkers, the presence of ether in ILs alkyl chain had increased the density of ILs due to the better entanglement of the ether group caused by its flexibility [37].

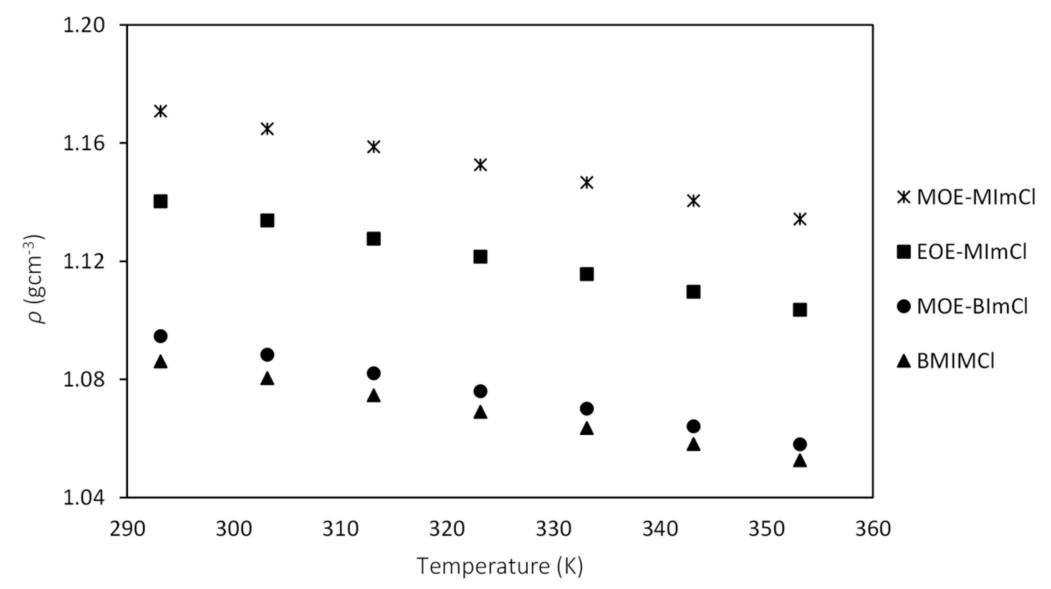

Figure 2. Density of ILs. 
Additionally, the experimental density values can be plotted to form a straight line by inserting the values according to empirical Equation (2) as follows:

$$
\ln \rho / \mathrm{gcm}^{-3}=\mathrm{b}-\alpha \mathrm{T} / \mathrm{K}
$$

where $b$ is empirical constant, and $\alpha$ is a thermal expansion coefficient. Figure 3 shows the empirical plot of ILs, while Table 3 lists the correlation coefficient $\left(R^{2}\right)$ and thermal expansion coefficient $(\alpha)$ values of ILs.

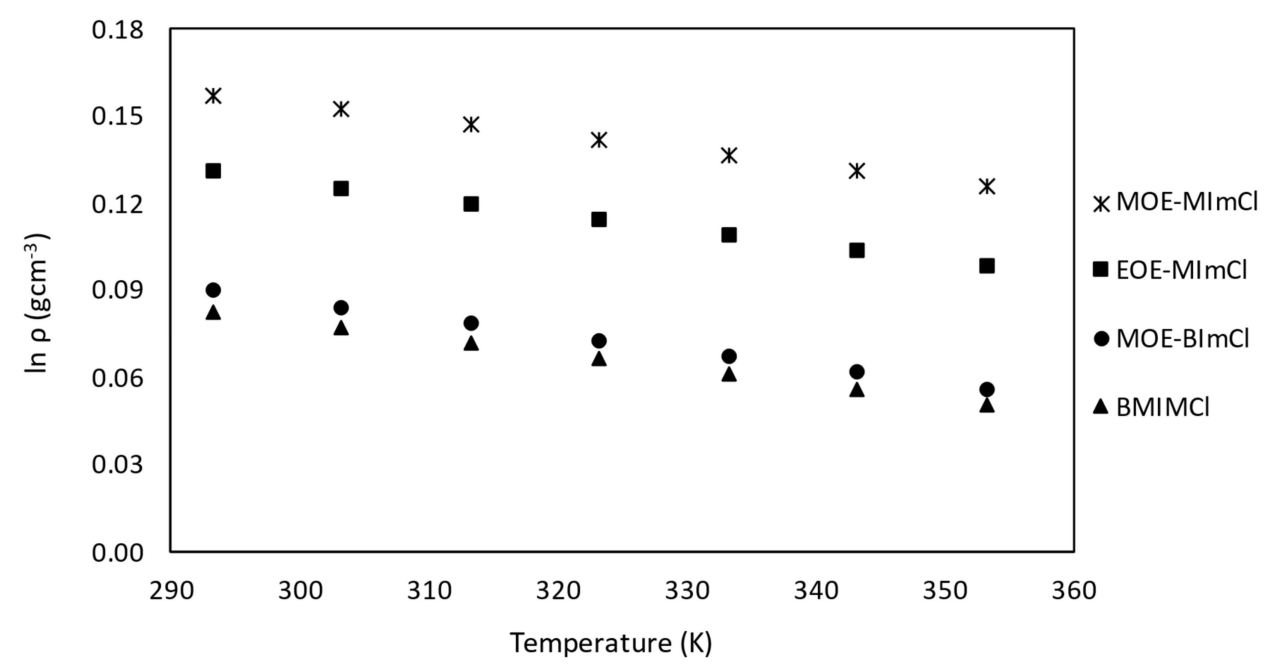

Figure 3. Empirical plot of ILs density.

Table 3. The value for linear fitting parameters $\left(R^{2}\right)$, thermal expansion coefficient $(\alpha)$, molar volume $(V)$, lattice energy $\left(\mathrm{U}_{\mathrm{POT}}\right)$ and standard molar entropy $\left(\mathrm{S}^{\circ}\right)$ for ILs.

\begin{tabular}{cccccc}
\hline Ionic Liquids & $\mathbf{R}^{\mathbf{2}}$ & $\boldsymbol{\alpha}$ & $\mathbf{V} \mathbf{~ ( n m ~}^{\mathbf{3}}$ ) & $\mathbf{U}_{\text {POT }}$ (kJ.mol) & $\mathbf{S}^{\circ}$ (J.K. mol \\
\hline MOE-MImCl & 0.9999 & $5.3 \times 10^{-4}$ & 0.2512 & 475.6455 & 342.5681 \\
EOE-MImCl & 0.9999 & $5.4 \times 10^{-4}$ & 0.2785 & 463.0592 & 376.6383 \\
MOE-BImCl & 1.0000 & $5.7 \times 10^{-4}$ & 0.3327 & 442.3739 & 444.2305 \\
[BMIM][Cl] & 0.9999 & $5.2 \times 10^{-4}$ & 0.26782 & 467.7663 & 363.3433 \\
\hline
\end{tabular}

As the $\mathrm{R}^{2}$ value is more than 0.99 , it was concluded that the experimental density values of ILs were well fitted with the proposed empirical linear equation. The values of $\alpha$ for all ILs were in the range of $5.2 \times 10^{-4}$ to $5.7 \times 10^{-4}$, which is lower than common solvents.

Besides this, the standard molar volume $(\mathrm{V})$, lattice energy $\left(\mathrm{U}_{\mathrm{POT}}\right)$ and standard molar entropy $\left(\mathrm{S}^{\circ}\right)$ at $\mathrm{T}=298.15 \mathrm{~K}$ can be calculated based on experimental density values using the following equations:

$$
\begin{gathered}
\mathrm{V}=\mathrm{M} /[(\mathrm{N} \cdot \rho)] \\
\mathrm{S}^{\circ}=1246.5(\mathrm{~V})+29.5 \\
\mathrm{U}_{\mathrm{POT}}=1981.2\left[(\rho / \mathrm{M})^{\wedge}(1 / 3)\right]+103.8
\end{gathered}
$$

where $\mathrm{M}$ is molar mass, $\mathrm{N}$ is Avogadro's constant $\left(6.0221 \times 10^{23}\right)$ and $\rho$ is the density. All the data gained from those equations were also listed in Table 3.

\subsubsection{Viscosity}

The dynamic viscosity of the synthesized ether-functionalized ILs and commercial $\mathrm{BMIMCl}$ as a comparison was carried out simultaneously with density measurement in the temperature range of $293.15 \mathrm{~K}$ to $353.15 \mathrm{~K}$ by using Anton Parr SVM 3000. The dynamic viscosities of ILs decreased exponentially with increasing temperature, as shown in Figure 4. The viscosity values decreased in the order of $\mathrm{MOE}-\mathrm{BImCl}>\mathrm{BMIMCl}>\mathrm{EOE}-\mathrm{MImCl}>$ 
MOE-MImCl. Generally, the viscosity of ether-functionalized ILs increased as the alky chain increased. To highlight the effect of the ether-functionalized group on the viscosity of ILs, a comparison was made between $\mathrm{MOE}-\mathrm{MImCl}$ and $\mathrm{BMIMCl}$, which contain a common ethyl chain in their structures. MOE-MImCl, which has an ether group, exhibited lower viscosity at all temperatures studied than that of BMIMCl. The existence of an oxygen atom with two lone pairs in the ILs alkyl chain causes an electron-donating effect that weakens the electrostatic interaction that exists between cation and anion and thus contributing to a reduction of MOE-MImCl viscosity [37].

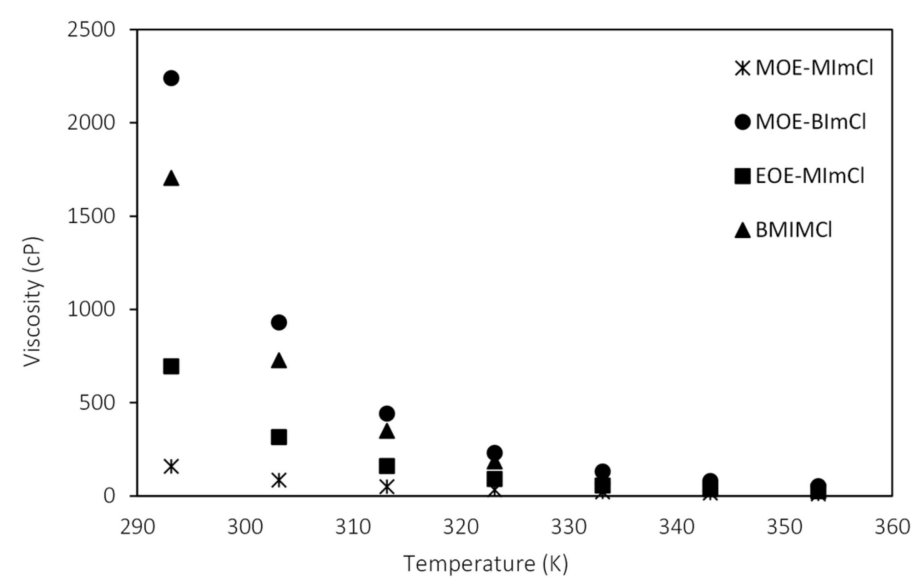

Figure 4. Viscosity for ILs.

Figure 5 presents the Arrhenius plot of ILs dynamic viscosity, which were done according to Equation (6):

$$
\ln \eta=\ln A+E_{n} / R T
$$

where $\eta$ is the dynamic viscosity, $E_{n}$ is the activation energy, and $R$ is the universal gas constant (8.314 J/mol.K).

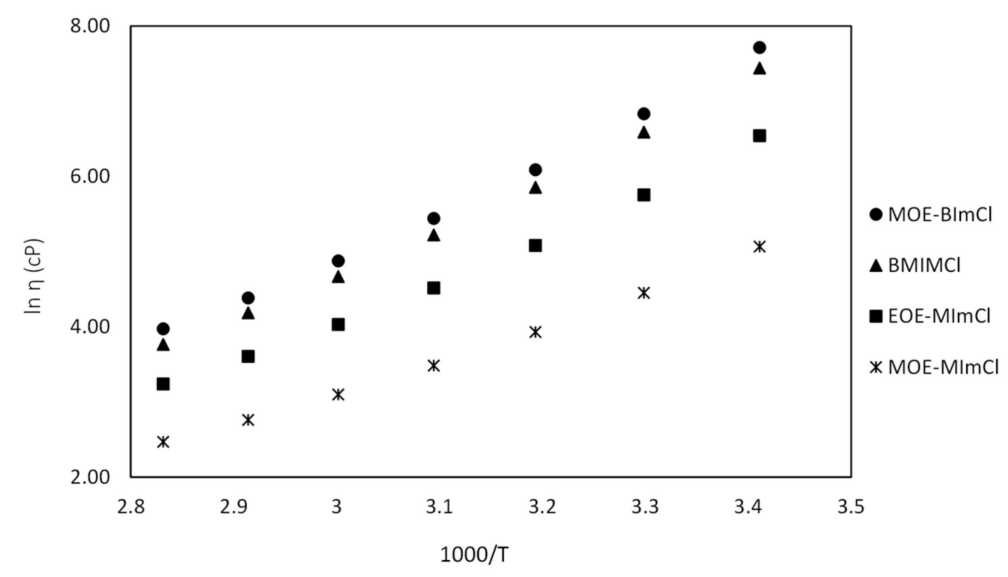

Figure 5. Arrhenius plot for ILs.

The values of $E_{n}, A$ and linear fitting parameters $\left(R^{2}\right)$ were calculated and tabulated in Table 4. The high $R^{2}$ values for all ILs, which are $>0.90$, indicate all ILs were well fitted with the proposed Arrhenius model. The $\mathrm{E}_{\mathrm{n}}$ values generated based on constructed Arrhenius plot represent the energy barrier that needs to be overcome by ion or mass transport. Generally, the viscosity flow is influenced by the value of $E_{n}$ owned by the fluid. The changes in $\mathrm{E}_{\mathrm{n}}$ will be constant with the changes in viscosity. Based on Table 4, by comparing two types of ILs with the same number of alkyl length, namely BMIMCl and $\mathrm{MOE}-\mathrm{MImCl}$, the incorporating of ether group in $\mathrm{MOE}-\mathrm{MImCl}$ has reduced its $\mathrm{E}_{\mathrm{n}}$ value as 
compared to BMIMCl. This indicates that the ether-functionalized group lowers the energy barrier and thus causes a reduction in the viscosity of the IL [34].

Table 4. The value for $R^{2}$ and activation energy $\left(E_{n}\right)$ for ILs.

\begin{tabular}{ccc}
\hline Ionic Liquids & $\mathbf{R}^{\mathbf{2}}$ & $\mathbf{E}_{\mathbf{n}} \mathbf{( k J \cdot \mathbf { m o l } ^ { - \mathbf { 1 } } )}$ \\
\hline MOE-MImCl & 0.9945 & 37.08 \\
EOE-MImCl & 0.9926 & 47.18 \\
MOE-BImCl & 0.9949 & 53.58 \\
BMIMCl & 0.9955 & 52.60 \\
\hline
\end{tabular}

\subsection{Dissolution of Bamboo Biomass in Ether-Functionalized ILs}

Generally, lignocellulosic biomass dissolution is a crucial step in the pretreatment process in order to extract its important constituents, namely cellulose, hemicellulose and lignin, which later can be converted into value-added chemicals. After a successful dissolution process, each constituent can be recovered by adding various solvents into the mixture containing dissolved lignocellulosic biomass and IL [38,39]. Nevertheless, this work is focusing on the improvement of the lignocellulosic biomass dissolution process utilizing ILs. In this work, the dissolution of bamboo was carried out in the synthesized ether-functionalized ILs to identify the best ether ILs for lignocellulosic biomass pretreatment. All parameters for the dissolution process were predetermined during previous studies [22]. Figure 6 shows the percentage of bamboo dissolved in all ILs. MOE-MImCl recorded the highest dissolution percentage, which is more than $90 \%$, as compared to other ether-functionalized ILs. As shown in the viscosity data previously, MOE-MImCl recorded the lowest viscosity values. Besides promoting the high mass transfer of solute during dissolution, a low viscosity environment is also preferable for the sonication technique [40]. In a low viscous solution, the cavitation occurs rapidly to generate microbubbles that later burst and provide higher energy for breaking down the cell wall of lignocellulosic biomass [41]. This process enhances the amount of biomass dissolved in MOE-MImCl within a shorter period. The lowest dissolution percentage of bamboo was recorded in EOM-MImCl, which is less than $10 \%$. EOM-MImCl exists in a solid state in which the ultrasonic waves were unable to be properly transmitted, thus causing an immediate reduction in power generated by ultrasonic.

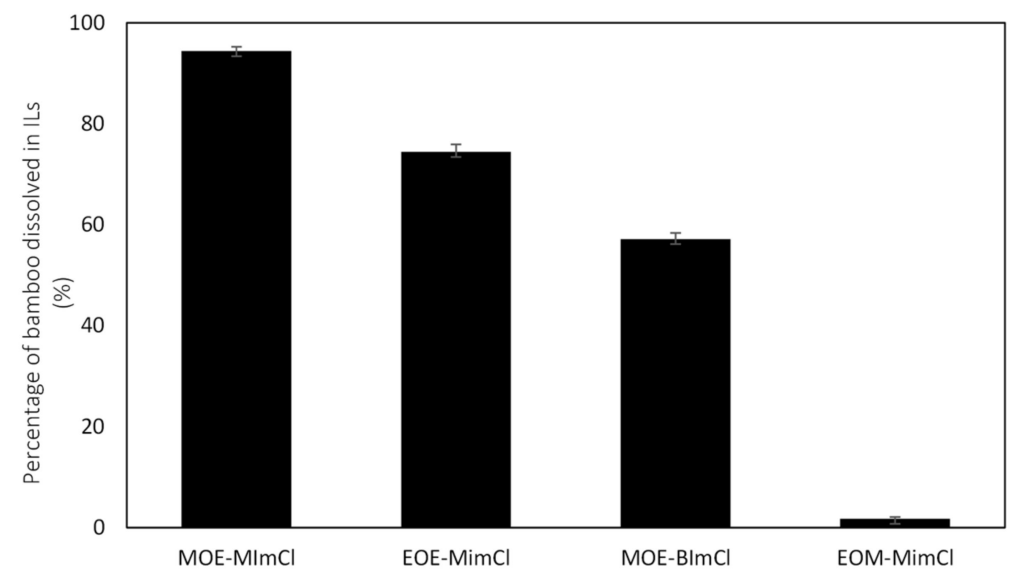

Figure 6. Percentage of bamboo dissolved in ether-functionalized ILs.

\subsubsection{RSM Study in Biomass Dissolution in ILs by Analysis on ANOVA}

RSM is applied for the optimization condition determination to improve the response to maximum or minimum [42,43]. In this case, RSM was employed to determine the 
optimum condition for bamboo dissolution in MOE-MImCl. The model proposed empirical relationship as shown in Equation (7) as follows:

$$
\mathrm{Y}=12.0658+2.58055 \mathrm{~A}-0.91528 \mathrm{~B}+3.20842 \mathrm{C}+0.27320 \mathrm{AB}-0.34650 \mathrm{AC}+0.018367 \mathrm{BC}
$$

in which $\mathrm{y}$ is the percentage of bamboo, $\mathrm{A}$ is ultrasonic amplitude, $\mathrm{B}$ is period of dissolution, and $\mathrm{C}$ is initial biomass loading. Table 5 shows the actual and predicted value for optimization experiments.

Table 5. Predicted vs. actual value for bamboo dissolution in 1-2(methoxyethyl)-3-methylimidazolium chloride (MOE-MImCl).

\begin{tabular}{cccccc}
\hline Run & $\begin{array}{c}\text { Amplitude } \\
\mathbf{( \% )}\end{array}$ & $\begin{array}{c}\text { Period of } \\
\text { Sonication } \\
\text { (min) }\end{array}$ & $\begin{array}{c}\text { Initial Biomass } \\
\text { Loading (wt \%) }\end{array}$ & $\begin{array}{c}\text { Dissolution } \\
\text { Percentage } \\
\text { (Predicted) }\end{array}$ & $\begin{array}{c}\text { Dissolution } \\
\text { Percentage } \\
\text { (Actual) }\end{array}$ \\
\hline 1 & 40 & 10 & 5.0 & 64.72 & 69.7 \\
2 & 20 & 35 & 8.0 & 26.14 & 23.11 \\
3 & 30 & 60 & 2.0 & 71.57 & 70.54 \\
4 & 30 & 35 & 5.0 & 53.42 & 59.89 \\
5 & 30 & 35 & 5.0 & 53.42 & 57.78 \\
6 & 30 & 60 & 8.0 & 35.07 & 36.64 \\
7 & 40 & 35 & 2.0 & 101.48 & 95.63 \\
8 & 30 & 35 & 5.0 & 53.42 & 53.78 \\
9 & 40 & 60 & 5.0 & 78.19 & 84.11 \\
10 & 30 & 10 & 2.0 & 74.52 & 74.43 \\
11 & 20 & 10 & 5.0 & 42.30 & 41.84 \\
12 & 30 & 10 & 8.0 & 32.50 & 35.02 \\
13 & 30 & 35 & 5.0 & 53.42 & 48.62 \\
14 & 30 & 35 & 5.0 & 53.42 & 50.87 \\
15 & 40 & 35 & 8.0 & 41.43 & 32.97 \\
16 & 20 & 35 & 2.0 & 44.61 & 44.19 \\
17 & 20 & 60 & 5.0 & 28.45 & 28.93 \\
\hline
\end{tabular}

Table 6 shows the analysis of variance (ANOVA) as the software has suggested a twofactor interaction (2FI) to describe the desired response, which is the dissolution percentage of bamboo. Generally, ANOVA provides information such as $p$-value, F-value and lack of fit to evaluate the adequacy of the model for ensuring the tolerable fit is achieved. The $p$-value is used to evaluate the significance of each variable while simultaneously determine the effect of each factor in which as the $p$-value is $<0.05$ (also known as Prob $>$ F-value), the model can be considered as significantly fitted [44]. In this study, the model $p$-value was $<0.0001$ with model F-value of 38.14 for dissolution percentage of bamboo indicates the significance of the suggested model. Other than this, the $p$-value also determines which variables provide a significant effect on the response. As shown in Table 6, the parameters $\mathrm{A}, \mathrm{C}$, and interactive parameters, which are $\mathrm{AB}$ and $\mathrm{AC}$, have $p$-values $<0.05$ suggesting a significant effect towards response. The values of $\mathrm{B}$ and $\mathrm{BC}$ are $>0.05$, implying no significant effect towards bamboo dissolution in IL. However, the insignificant variable and interactive effect cannot be omitted in order to retain the model hierarchy as the other variables are highly significant.

Meanwhile, lack of fit that is used for verifying whether systematic or random error responsible for deviation of expected values from the measured one had a $p$-value of 0.3792 , which indicates the model also fits well with the experiments [45]. An adequate precision is a signal-to-noise ratio that measures the range of predicted response relative to an associate error with a value greater than four is desired. Our work displays the value of 22.354 confirmed an adequate signal. The coefficient of determination $\left(R^{2}\right)$ is one of the main criteria to check the adequacy of the model as it indicates the goodness of the data fit in the model. The closer the value of predicted data by the model to experimental data, the closer the value of $R^{2}$ into 1 . In this study, the value of $R^{2}$ is 0.9581 , which signage that $95.81 \%$ of the percentage of bamboo 
dissolution is attributed to the considered variables. A high $\mathrm{R}^{2}$ value also implies a strong correlation between actual and predicted value, as shown in Figure 7. Moreover, the model fitting can be discussed based on the values of adjusted coefficient determination (adj- $\mathrm{R}^{2}$ ) and predicted coefficient determination (pred- $R^{2}$ ), in which the difference between both values should be within 0.2 for the model to be reasonable [45]. The values of adj- $R^{2}$ and pred- $R^{2}$, which are 0.9330 and 0.84 , also supported the previous $R^{2}$ value.

Table 6. ANOVA table.

\begin{tabular}{cccccc}
\hline Source of Variations & $\begin{array}{c}\text { Sum of } \\
\text { Squares }\end{array}$ & $\begin{array}{c}\text { Degree of } \\
\text { Freedom }\end{array}$ & $\begin{array}{c}\text { Mean } \\
\text { Square }\end{array}$ & F-Value & $p$-Value \\
\hline Model & 6313.83 & 6 & 1052.30 & 38.14 & $<0.0001$ \\
A-ultrasonic amplitude & 2604.25 & 1 & 2604.25 & 94.39 & $<0.0001$ \\
B-period of dissolution & 0.074 & 1 & 0.074 & $2.686 \times 10^{-3}$ & 0.9597 \\
C-initial sample-loading & 3083.09 & 1 & 3083.09 & 111.74 & $<0.0001$ \\
AB & 186.60 & 1 & 186.60 & 6.76 & 0.0265 \\
AC & 432.22 & 1 & 432.22 & 15.67 & 0.0027 \\
BC & 7.59 & 1 & 7.59 & 0.28 & 0.6114 \\
Residual & 275.91 & 10 & 27.59 & & Not \\
Lack of fit & 188.31 & 6 & 31.39 & 1.43 & 0.3792 \\
\end{tabular}

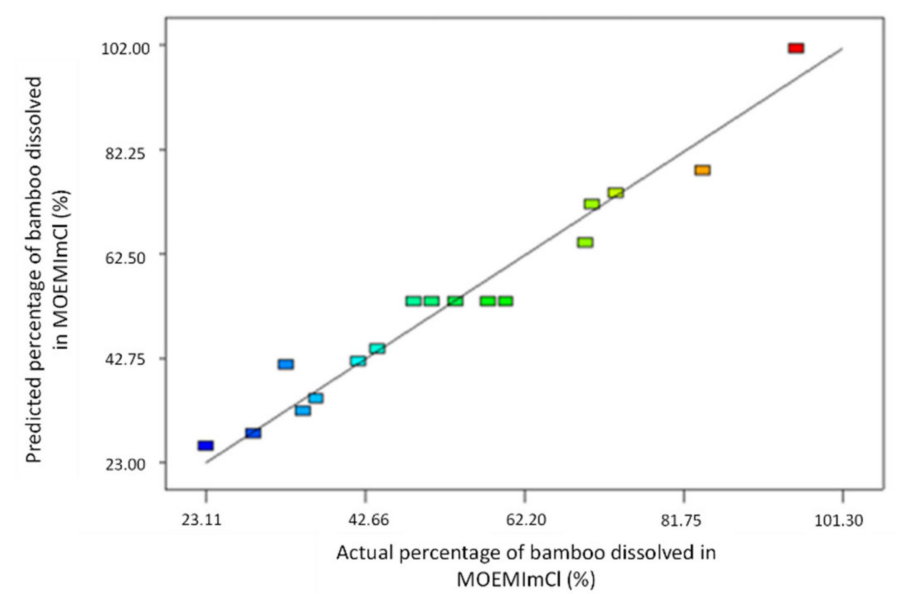

Figure 7. Actual vs. predicted plot for response surface methodology (RSM) of bamboo dissolution in MOE-MImCl.

3.2.2. Effect of Ultrasonic Amplitude, Period of Dissolution and Initial Sample-Loading towards Bamboo Dissolution in MOE-MImCl

The highest percentage for bamboo dissolved, which is $95.63 \%$, was recorded at $40 \%$ amplitude with $2 \mathrm{wt} \%$ initial bamboo-loading at $35 \mathrm{~min}$ period of sonication. Meanwhile, increasing the initial bamboo-loading to $8 \mathrm{wt} \%$ while sonicated at a minimum amplitude of $20 \%$ reduced the percentage of dissolution to 23.11 within the same reaction time. The contour plot in Figure 8 describes the relationship between each variable towards lignocellulosic biomass dissolution.

In our work, the initial reaction temperature was recorded at $27^{\circ} \mathrm{C}$. As the mixture of bamboo/ILs was exposed into sonication, the final reaction temperature has reached about $80{ }^{\circ} \mathrm{C}$ and $120^{\circ} \mathrm{C}$ at $20 \%$ and $40 \%$ of ultrasonic amplitude, respectively. Generally, ultrasonic amplitude provides a significant effect on the reaction temperature. The reaction temperature was found to be proportional to the ultrasonic amplitude, and this relationship has been further elaborated in our previous publication [46]. As the temperature is highly dependent on ultrasonic amplitude, thus in this work, we focus on varying the ultrasonic amplitude. Table 5 indicates that the ultrasonic amplitude used in each reaction has a significant influence on the dissolution percentage of bamboo in ILs. The maximum ampli- 
tude of $40 \%$ with $2 \mathrm{wt} \%$ of bamboo-loading at $35 \mathrm{~min}$ period of dissolution had resulted in a high percentage of dissolved bamboo, which is $95.63 \%$. However, the percentage of biomass dissolved had been reduced to $44.19 \%$ as the ultrasonic amplitude decreased to $20 \%$ at the same initial loading and period of dissolution.
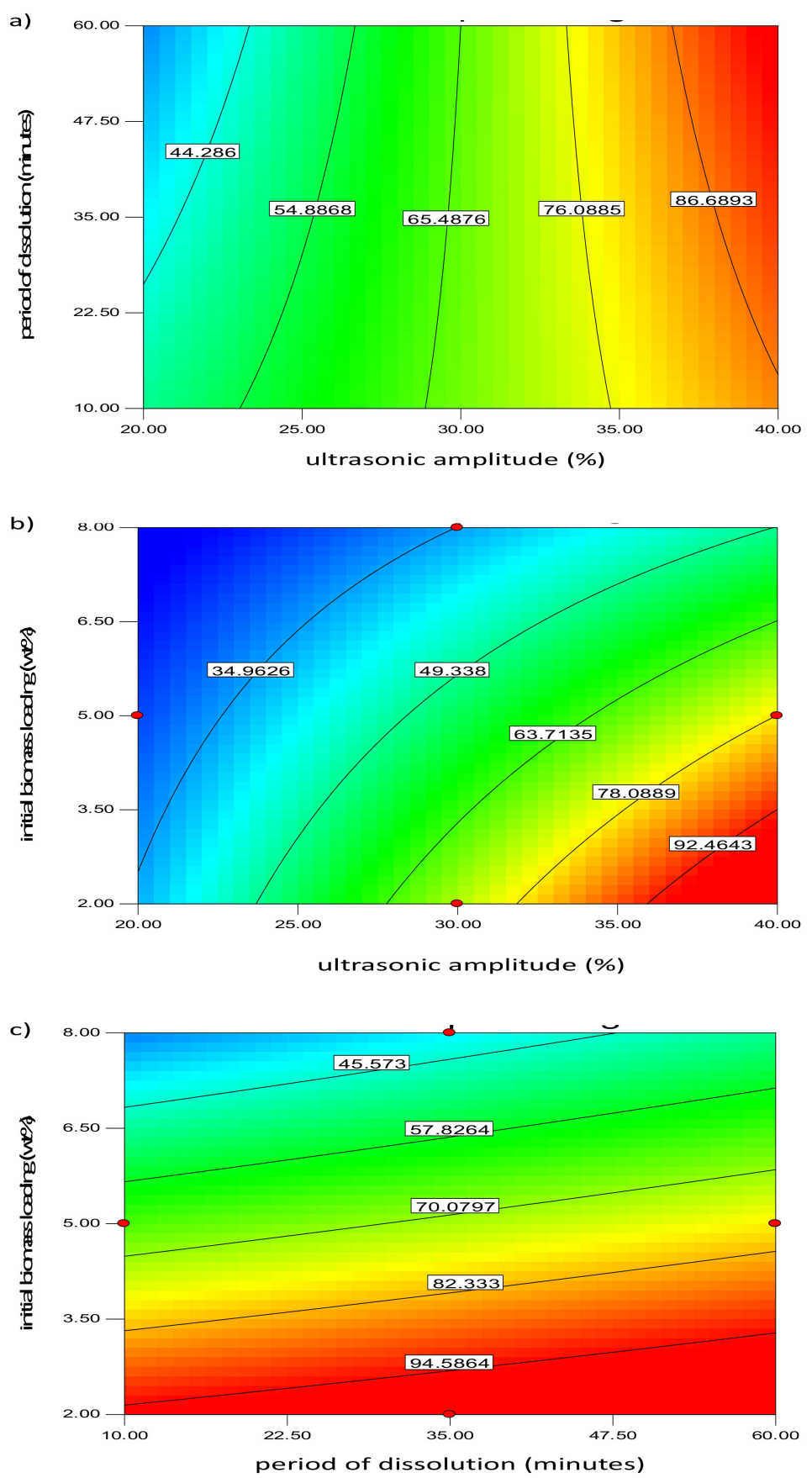

Figure 8. Contour plot for the effect of each parameter for bamboo dissolution in MOE-MImCl; (a) plot of period of dissolution against ultrasonic amplitude, (b) plot of initial biomass loading against ultrasonic amplitude and (c) plot of initial biomass loading against period of dissolution.

The relationship between the period of dissolution and the percentage of bamboo dissolved in MOE-MImCl not showing a constant trend as different initial loading shown different results. For example, at initial loading of $2.0 \mathrm{wt} \%$ with $30 \%$ amplitude and $10 \mathrm{~min}$ of reaction time, the dissolution percentage of bamboo was $74.43 \%$. As the reaction time increased to $60 \mathrm{~min}$, the percentage of bamboo dissolved slightly decreased to $70.54 \%$. In 
the meantime, this trend was reversed for maximum initial bamboo-loading of $8.0 \mathrm{wt} \%$ within the same ultrasonic amplitude. At 10 min of reaction time, $35.02 \%$ of bamboo had been dissolved. As the reaction was extended to $60 \mathrm{~min}$, the percentage of bamboo dissolved had increased to $36.64 \%$. Based on this study, it can be concluded that a longer reaction time does not assure a higher dissolution percentage as amplitude and initial sample-loading provide a more significant effect.

However, a negative correlation was observed between the initial biomass-loading and the percentage of biomass dissolved. For example, $8 \mathrm{wt} \%$ of initial biomass-loading had resulted in less than $35 \%$ of biomass had dissolved in ILs. Meanwhile, the minimum initial biomass-loading of $2 \mathrm{wt} \%$ resulted in more than $90 \%$ of biomass dissolved in the IL within the same amplitude of $40 \%$ and period of sonication at $35 \mathrm{~min}$. The same result was obtained by Muhammad et al. in which the lignin recovery decreased as the loading of bamboo increased [47]. Cruz et al., indicated that an increase in initial biomass-loading could cause an increase in the IL/biomass mixture's viscosity [48]. This, in turn, contributes to a low dissolution percentage due to the reduction of the ILs ion mobility, which restricts the interaction of IL with biomass.

For the optimization process, the response was set at maximum while ultrasonic amplitude was to be in the range while a minimum period of dissolution was chosen since, in any dissolution process, a shorter period of dissolution with high biomass loading is preferable. Although the maximum dissolution was achieved at the initial biomass-loading at $2 \mathrm{wt} \%, 3 \mathrm{wt} \%$ of initial biomass-loading has been chosen due to a higher chance of extracting biomass constituents. In order to further verify the model, another experiment was conducted based on the optimization condition suggested by the software to calculate the relative error. The relative error was 5.83, which is acceptable for model verification.

\subsubsection{Comparison Study on Bamboo Dissolution in ILs}

For comparison study, the bamboo was dissolved in BMIMCl based on optimum condition obtained in the previous RSM study. The result was then compared with MOE-MImCl. Figure 9 shows the percentage of bamboo dissolved in both ILs. It was identified that etherfunctionalized ILs successfully dissolved $96.45 \%$ of bamboo compared to BMIMCl, which recorded $78.35 \%$ of dissolution. Previous studies suggested that the lignocellulosic biomass dissolution in ILs was caused by several factors such as temperature, the particle size of biomass, time and viscosity of ILs [49,50]. The low viscosity property of MOE-MImCl compared to $\mathrm{BMIMCl}$ was discussed in the previous section. Apparently, the low viscosity of $\mathrm{MOE}-\mathrm{MImCl}$ becomes a major contribution in improving the bamboo dissolution in ILs. Low viscosity MOE-MImCl boosts the mass transfer of solute, thus leads to a higher percentage of dissolution. The same results were obtained by Fukaya et al. in which low viscosity of ally-based ILs displayed a better dissolution ability compared to alkyl-based ILs [19]. Other than this, the dissolution of bamboo in ILs was done by implementing a direct probe sonication technique. Generally, sonication is preferably done in a low viscous medium in order to maximize cavitation during the process. In a highly viscous medium such as BMIMCl, the shockwave will not be able to transfer properly, which leads to a reduction in cavitation, thus causes low dissolution of bamboo.

Besides this, the lignocellulosic bamboo dissolution involves the disruption of the hydrogen bonds network in cellulose. Numerous studies have shown that anions do play a huge role in determining the ability of ILs to break chemical bonds in lignocellulosic biomass. However, current works by Okushita et al. and Chang et al. have confirmed the involvement of cation in the disruption of hydrogen bonds in lignocellulosic biomass based on FTIR and solid-state NMR studies [51,52]. Apart from this, a simulation study by Liu and coworkers had revealed the existence of hydrophobic interaction between imidazolium cation with D-glucose in cellulose. This interaction also plays an important role in ensuring lignocellulosic biomass dissolution occurred in ILs [53]. In the case of MOE-MImCl, the oxygen atom of the methoxy group with two lone pairs acts as an electron-withdrawing group, thus becomes an extra point for the formation of hydrogen bond compared with 
$\mathrm{BMIMCl}$. However, the presence of ether group in MOE-MImCl also causes the IL to become more sensitive towards the presence of moisture and consequently owns a higher moisture content compared to BMIMCl. Besides this, the reaction was done in an open system, which may increase the probability of ILs attracting moisture. The presence of extra moisture is well known to reduce the dissolution ability of ILs [54]. Therefore, the moisture in $\mathrm{MOE}-\mathrm{MImCl}$ was dried under vacuum to ensure minimum content of moisture to avoid any disturbance to the dissolution process.

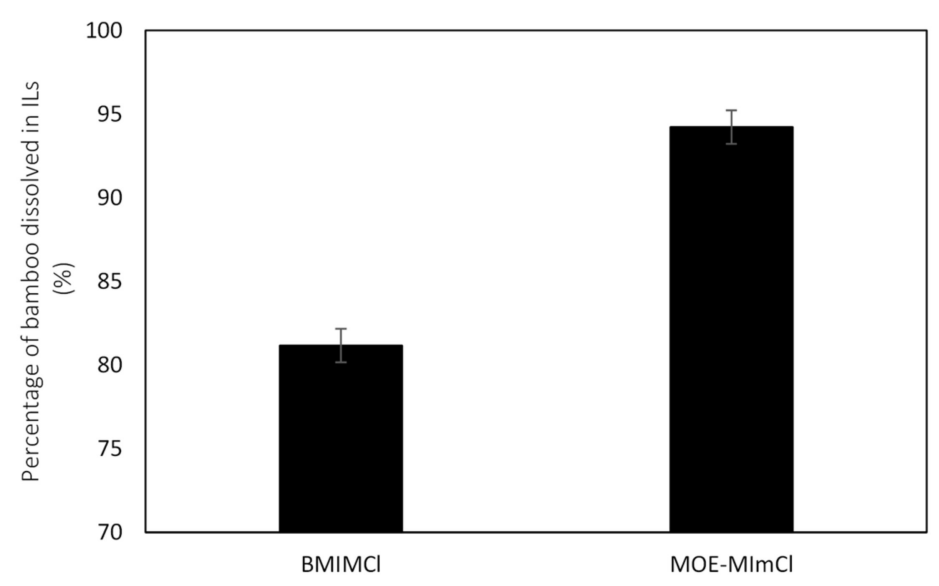

Figure 9. Dissolution of bamboo in $\mathrm{MOE}-\mathrm{MImCl}$ and [BMIM][Cl].

\section{Conclusions}

The presence of ether-the functionalized group-was proven to alter the thermal and physicochemical properties of ILs. Further studies on the dissolution of bamboo biomass have shown that the highest amount of bamboo dissolved was achieved in MOE$\mathrm{MImCl}$, which has the lowest viscosity value as compared to other ILs. Furthermore, the optimization study by using RSM has proven that the amplitude and the initial loading of bamboo biomass play significant roles in the dissolution process. However, more research works need to be carried out to extract constituents in lignocellulosic biomass with a more effective technique to improve the dissolution.

Author Contributions: Conceptualization, A.H.A.R. and N.M.Y.; methodology, A.H.A.R., W.S.W.H., A.S. and N.M.; validation, N.M.Y.; writing—original draft preparation, A.H.A.R.; writing-review and editing, N.M.Y.; supervision, N.M.Y. All authors have read and agreed to the published version of the manuscript.

Funding: This research was funded by the Petroleum Research Fund, grant number 0153AB-A30.

Institutional Review Board Statement: Not applicable.

Informed Consent Statement: Not applicable.

Data Availability Statement: The data that support the findings in the present study are available from the corresponding author upon request.

Acknowledgments: Financial assistance and support from Universiti Teknologi PETRONAS and Centre of Research in Ionic Liquids (CORIL), UTP, are greatly acknowledged.

Conflicts of Interest: The authors declare no conflict of interest.

\section{References}

1. Owusu, P.A.; Asumadu-Sarkodie, S. A review of renewable energy sources, sustainability issues and climate change mitigation. Cogent. Eng. 2016, 3, 1-14. [CrossRef]

2. Carlsson, A.S. Plant oils as feedstock alternatives to petroleum-A short survey of potential oil crop platforms. Biochimie 2009, 91, 665-670. [CrossRef] [PubMed]

3. Roddy, D.J. Biomass in a petrochemical world. Interface Focus 2013, 3, 1-8. [CrossRef] [PubMed] 
4. Stastical Review of World Energy. June 2014. Available online: http://large.stanford.edu/courses/2014/ph240/milic1/docs / bpreview.pdf (accessed on 15 August 2019).

5. Cai, J.; He, Y.; Yu, X.; Banks, S.W.; Yang, Y.; Zhang, X.; Yu, Y.; Liu, R.; Bridgwater, A.V. Review of physicochemical properties and analytical characterization of lignocellulosic biomass. Renew. Sustain. Energy Rev. 2017, 76, 309-322. [CrossRef]

6. Dhyani, V.; Bhaskar, T. A comprehensive review on the pyrolysis of lignocellulosic biomass. Renew. Energy 2018, 129, 695-716. [CrossRef]

7. Arevalo-Gallegos, A.; Ahmad, Z.; Asgher, M.; Parra-Saldivar, R.; Iqbal, H.M. Lignocellulose: A sustainable material to produce value-added products with a zero waste approach-A review. Int. J. Biol. Macromol. 2017, 99, 308-318. [CrossRef]

8. Zhang, K.; Pei, Z.; Wang, D. Organic solvent pretreatment of lignocellulosic biomass for biofuels and biochemicals: A review. Bioresour. Technol. 2016, 199, 21-33. [CrossRef]

9. Sun, Z.; Fridrich, B.L.; de Santi, A.; Elangovan, S.; Barta, K. Bright side of lignin depolymerization: Toward new platform chemicals. Chem. Rev. 2018, 118, 614-678. [CrossRef]

10. Wendisch, V.F.; Kim, Y.; Lee, J.-H. Chemicals from lignin: Recent depolymerization techniques and upgrading extended pathways. Curr. Opin. Green Sustain. Chem. 2018, 14, 33-39. [CrossRef]

11. Zhang, J.; Xu, L.; Yu, J.; Wu, J.; Zhang, X.; He, J.; Zhang, J. Understanding cellulose dissolution: Effect of the cation and anion structure of ionic liquids on the solubility of cellulose. Sci. China Chem. 2016, 59, 1421-1429. [CrossRef]

12. Antunes, F.A.F.; Chandel, A.K.; Teran-Hilares, R.; Ingle, A.P.; Rai, M.; dos Santos Milessi, T.S.; da Silva, S.S.; dos Santos, J.C. Overcoming challenges in lignocellulosic biomass pretreatment for second-generation (2G) sugar production: Emerging role of nano, biotechnological and promising approaches. 3 Biotech 2019, 9, 1-17. [CrossRef] [PubMed]

13. Brodeur, G.; Yau, E.; Badal, K.; Collier, J.; Ramachandran, K.B.; Ramakrishnan, S. Chemical and physicochemical pretreatment of lignocellulosic biomass: A review. Enzyme Res. 2011, 2011, 787532. [CrossRef] [PubMed]

14. Hassan, S.S.; Williams, G.A.; Jaiswal, A.K. Emerging technologies for the pretreatment of lignocellulosic biomass. Bioresour. Technol. 2018, 262, 310-318. [CrossRef] [PubMed]

15. Lei, Z.; Chen, B.; Koo, Y.-M.; MacFarlane, D.R. Introduction: Ionic liquids. Chem. Rev. 2017, 117, 6633-6635. [CrossRef] [PubMed]

16. Mahmood, H.; Moniruzzaman, M.; Yusup, S.; Akil, H.M. Pretreatment of oil palm biomass with ionic liquids: A new approach for fabrication of green composite board. J. Clean. Prod. 2016, 126, 677-685. [CrossRef]

17. Sivapragasam, M.; Moniruzzaman, M.; Goto, M. Recent advances in exploiting ionic liquids for biomolecules: Solubility, stability and applications. Biotechnol. J. 2016, 11, 1000-1013. [CrossRef]

18. Medronho, B.; Romano, A.; Miguel, M.G.; Stigsson, L.; Lindman, B. Rationalizing cellulose (in) solubility: Reviewing basic physicochemical aspects and role of hydrophobic interactions. Cellulose 2012, 19, 581-587. [CrossRef]

19. Fukaya, Y.; Sugimoto, A.; Ohno, H. Superior solubility of polysaccharides in low viscosity, polar, and halogen-free 1, 3dialkylimidazolium formates. Biomacromolecules 2006, 7, 3295-3297. [CrossRef]

20. Zhang, H.; Wu, J.; Zhang, J.; He, J. 1-Allyl-3-methylimidazolium chloride room temperature ionic liquid: A new and powerful nonderivatizing solvent for cellulose. Macromolecules 2005, 38, 8272-8277. [CrossRef]

21. Siqueira, L.J.; Ribeiro, M.C. Alkoxy chain effect on the viscosity of a quaternary ammonium ionic liquid: Molecular dynamics simulations. J. Phys. Chem. B 2009, 113, 1074-1079. [CrossRef]

22. Rahim, A.H.A.; Yunus, N.M.; Man, Z.; Sarwono, A.; Hamzah, W.S.W.; Wilfred, C.D. Ultrasonic assisted dissolution of bamboo biomass using ether-functionalized ionic liquid. In Proceedings of the International Conference on Applied Science and Technology, Penang, Malaysia, 10-12 April 2018; Nifa, F.A.A., Chong, K.L., Hussain, A., Eds.; AIP Publishing: New York, NY, USA, 2018.

23. Tauler, R.; Walczak, B.; Brown, S.D. Comprehensive Chemometrics: Chemical and Biochemical Data Analysis, 2nd ed.; Elsevier: Amsterdam, The Netherlands, 2020; ISBN 9780444641656.

24. Bezerra, M.A.; Santelli, R.E.; Oliveira, E.P.; Villar, L.S.; Escaleira, L.A. Response surface methodology (RSM) as a tool for optimization in analytical chemistry. Talanta 2008, 76, 965-977. [CrossRef] [PubMed]

25. Sarwono, A.; Man, Z.; Muhammad, N.; Khan, A.S.; Hamzah, W.S.W.; Rahim, A.H.A.; Ullah, Z.; Wilfred, C.D. A new approach of probe sonication assisted ionic liquid conversion of glucose, cellulose and biomass into 5-hydroxymethylfurfural. Ultrason. Sonochem. 2017, 37, 310-319. [CrossRef] [PubMed]

26. Sun, N.; Rahman, M.; Qin, Y.; Maxim, M.L.; Rodríguez, H.; Rogers, R.D. Complete dissolution and partial delignification of wood in the ionic liquid 1-ethyl-3-methylimidazolium acetate. Green Chem. 2009, 11, 646-655. [CrossRef]

27. Behera, S.K.; Meena, H.; Chakraborty, S.; Meikap, B. Application of response surface methodology (RSM) for optimization of leaching parameters for ash reduction from low-grade coal. Int. J. Min. Sci. Technol. 2018, 28, 621-629. [CrossRef]

28. Chauhan, V.; Singh, S.; Kamboj, R. Self-Assembly and thermal stability of ether-functionalized imidazolium ionic liquids. Ind. Eng. Chem. Res. 2014, 53, 13247-13255. [CrossRef]

29. Chen, Z.; Huo, Y.; Cao, J.; Xu, L.; Zhang, S. Physicochemical properties of ether-functionalized ionic liquids: Understanding their irregular variations with the ether chain length. Ind. Eng. Chem. Res. 2016, 55, 11589-11596. [CrossRef]

30. Tang, S.; Baker, G.A.; Zhao, H. Ether- and alcohol-functionalized task-specific ionic liquids: Attractive properties and applications. Chem. Soc. Rev. 2012, 41, 4030-4066. [CrossRef]

31. Efimova, A.; Hubrig, G.; Schmidt, P. Thermal stability and crystallization behavior of imidazolium halide ionic liquids. Thermochim. Acta 2013, 573, 162-169. [CrossRef] 
32. Chai, M.; Jin, Y.; Fang, S.; Yang, L.; Hirano, S.-I.; Tachibana, K. Ether-functionalized pyrazolium ionic liquids as new electrolytes for lithium battery. Electrochim. Acta 2012, 66, 67-74. [CrossRef]

33. Zhang, Z.; Salih, A.A.; Li, M.; Yang, B. Synthesis and characterization of functionalized ionic liquids for thermal storage. Energy Fuels 2014, 28, 2802-2810. [CrossRef]

34. Chen, Z.; Liu, S.; Li, Z.; Zhang, Q.; Deng, Y. Dialkoxy functionalized quaternary ammonium ionic liquids as potential electrolytes and cellulose solvents. New J. Chem. 2011, 35, 1596-1606. [CrossRef]

35. Fredlake, C.P.; Crosthwaite, J.M.; Hert, D.G.; Aki, S.N.; Brennecke, J.F. Thermophysical properties of imidazolium-based ionic liquids. J. Chem. Eng. Data 2004, 49, 954-964. [CrossRef]

36. Lee, C.-P.; Peng, J.-D.; Velayutham, D.; Chang, J.; Chen, P.-W.; Suryanarayanan, V.; Ho, K.-C. Trialkylsulfonium and tetraalkylammonium cations-based ionic liquid electrolytes for quasi-solid-state dye-sensitized solar cells. Electrochim. Acta 2013, 114, 303-308. [CrossRef]

37. Zhang, J.; Fang, S.; Qu, L.; Jin, Y.; Yang, L.; Hirano, S.-I. Synthesis, characterization, and properties of ether-functionalized 1, 3-dialkylimidazolium ionic liquids. Ind. Eng. Chem. Res. 2014, 53, 16633-16643. [CrossRef]

38. Lan, W.; Liu, C.F.; Sun, R.C. Fractionation of bagasse into cellulose, hemicelluloses, and lignin with ionic liquid treatment followed by alkaline extraction. J. Agric. Food Chem. 2011, 59, 8691-8701. [CrossRef] [PubMed]

39. Neubert, L.; Sunthornvarabhas, J.; Sakulsombat, M.; Sriroth, K. Delignification and fractionation of sugarcane baggase with ionic liquids. Cell Chem. Technol. 2020, 54, 301-318. [CrossRef]

40. Wu, T.Y.; Guo, N.; Teh, C.Y.; Hay, J.X.W. Theory and fundamentals of ultrasound. In Advances in Ultrasound Technology for Environmental Remediation; Springer: Berlin, Germany, 2013; pp. 5-12. ISBN 978-94-007-5533-8.

41. Kuna, E.; Behling, R.; Valange, S.; Chatel, G.; Colmenares, J.C. Sonocatalysis: A potential sustainable pathway for the valorization of lignocellulosic biomass and derivatives. Top. Curr. Chem. 2017, 375, 1-20. [CrossRef]

42. Khuri, A.I.; Mukhopadhyay, S. Response surface methodology. Wiley Interdiscip. Rev. Comput. Stat. 2010, 2, 128-149. [CrossRef]

43. Myers, R.H.; Montgomery, D.C.; Anderson-Cook, C.M. Response surface methodology. In Response Surface Methodology: Process and Product Optimization Using Designed Experiments, 4th ed.; John Wiley \& Sons: Hoboken, NJ, USA, 2016; ISBN 978-1-118-91601-8.

44. Trinh, L.T.P.; Lee, Y.-J.; Lee, J.-W.; Lee, W.-H. Optimization of ionic liquid pretreatment of mixed softwood by response surface methodology and reutilization of ionic liquid from hydrolysate. Biotechnol. Bioprocess Eng. 2018, 1-10. [CrossRef]

45. Houshmand, A.; Daud, W.M.A.W.; Shafeeyan, M.S. Tailoring the surface chemistry of activated carbon by nitric acid: Study using response surface method. Bull. Chem. Soc. Jpn. 2011, 84, 1251-1260. [CrossRef]

46. Rahim, A.H.A.; Man, Z.; Sarwono, A.; Muhammad, N.; Khan, A.S.; Hamzah, W.S.W.; Yunus, N.M.; Elsheikh, Y.A. Probe sonication assisted ionic liquid treatement for rapid dissolution of lignocellulosic biomass. Cellulose 2020, 27, 2135-2148. [CrossRef]

47. Muhammad, N.; Man, Z.; Bustam, M.A.; Mutalib, M.A.; Rafiq, S. Investigations of novel nitrile-based ionic liquids as pre-treatment solvent for extraction of lignin from bamboo biomass. J. Ind. Eng. Chem. 2013, 19, 207-214. [CrossRef]

48. Cruz, A.G.; Scullin, C.; Mu, C.; Cheng, G.; Stavila, V.; Varanasi, P.; Xu, D.; Mentel, J.; Chuang, Y.-D.; Simmons, B.A. Impact of high biomass loading on ionic liquid pretreatment. Biotechnol. Biofuel. 2013, 6, 1-59. [CrossRef] [PubMed]

49. Leskinen, T.; King, A.W.; Kilpeläinen, I.; Argyropoulos, D.S. Fractionation of lignocellulosic materials using ionic liquids: Part 2. Effect of particle size on the mechanisms of fractionation. Ind. Eng. Chem. Res. 2013, 52, 3958-3966. [CrossRef]

50. Li, Y.; Wang, J.; Liu, X.; Zhang, S. Towards a molecular understanding of cellulose dissolution in ionic liquids: Anion/cation effect, synergistic mechanism and physicochemical aspects. Chem. Sci. 2018, 9, 4027-4043. [CrossRef]

51. Okushita, K.; Chikayama, E.; Kikuchi, J. Solubilization mechanism and characterization of the structural change of bacterial cellulose in regenerated states through ionic liquid treatment. Biomacromolecules 2012, 13, 1323-1330. [CrossRef]

52. Chang, H.-C.; Zhang, R.-L.; Hsu, D.-T. The effect of pressure on cation-cellulose interactions in cellulose/ionic liquid mixtures. Phys. Chem. Chem. Phys. 2015, 17, 27573-27578. [CrossRef]

53. Liu, H.; Sale, K.L.; Holmes, B.M.; Simmons, B.A.; Singh, S. Understanding the interactions of cellulose with ionic liquids: A molecular dynamics study. J. Phys. Chem. B 2010, 114, 4293-4301. [CrossRef]

54. Pang, Z.; Dong, C.; Pan, X. Enhanced deconstruction and dissolution of lignocellulosic biomass in ionic liquid at high water content by lithium chloride. Cellulose 2015, 23, 323-338. [CrossRef] 